\title{
A Study on the Problems faced by Women Entrepreneurs using Neutrosophic Associative Fuzzy Cognitive Dynamical System
}

\author{
A. Victor Devadoss \\ Department of Mathematics \\ Loyola College \\ Chennai-600034
}

\author{
M. Rekha \\ Department of Mathematics \\ Loyola College \\ Chennai-600034
}

\begin{abstract}
Women Entrepreneurship has been recognised as an important source of economic growth for developing the country. Women Entrepreneurs have involved themselves in different sectors as it helps to creates accomplishment by finding their own individuality in the society.The aim of this paper is to study the problems of faced by women entrepreneurs and their effects. Section one deals introduction. Section two gives the definitions. Section three describes the adaptation of the problem. Ultimately section five reveals conclusion.
\end{abstract}

\section{Keywords}

Women Entrepreneur, Neutrosophic Associative Memories, Fuzzy Cognitive Map, Bihidden patterns, Limit cycle

\section{INTRODUCTION}

L.A.Zadeh introduced Fuzzy Set theory in 1965 to deal with vagueness and imprecise [1]. In 1976. Axelrod [2] used cognitive maps to study decision making in social and political system. Then kosko enhanced cognitive maps by considering the fuzzy values for the concept of cognitive map and fuzzy degree of interrelationships between the concepts. Neutrosophic models are fuzzy models which allow the factor of indeterminacy. Neutrosophic Associative Memories (NAM) was introduced by Vasantha Kandasamy and Floretin Smarandache in 2005 and Fuzzy Cognitive Maps (FCM) were pioneered by Bart Kosko in 1986[6]. Some bimodels were introduced namely Fuzzy Cognitive Relational map [3], Bidirectional Associative Fuzzy Cognitive Dynamical system [4], Bidirectional Associative Neutrosophic Cognitive Dynamical system [5] and Neutrosophic 'Associative Fuzzy Cognitive Map [6].Women entrepreneurs is women or group of women who creates and manages the business as it helps to empower them to increase the economical strength and identity in the society. According to Women Business Ownership index, India was in low position(41.7 points) among 54 countries. India gives low opportunities for women in leadership, participation in the workforce. Mostly women are prone to shutting down their business due to lack of finance. Lack of education, Cultural bias and weak in technological are some key impediments for raising their position in the business[7].Neutrosophic Associative Fuzzy Cognitive Map(NAFCM) was chosen to study the problems of women entrepreneurs and effects faced by them in the society and works on when the study is in unsupervised one. The dynamical bisystem NAFCM consist of NAM dynamical system and FCM dynamical system by giving stage by stage effects of the attributes . NAM consists pair of attributes where indeterminacy occurs in the relationship by dealing with the problems of women Entrepreneurs and effects faced by them. In FCM, one set of attributes involves the problems faced by women entrepreneurs. This bimodel helps to captures the bihidden pattern for the problems faced by them.

\section{NEUTROSOPHIC FUZZY COGNITI VE BIMODEL}

\subsection{Definition}

$M$ is said to be biset if $M=M_{1} \cup M_{2}$ where $M_{1}, M_{2}$ are nonempty sets.

Example: $\mathrm{M}=\left(\begin{array}{lll}3 & 1 & 7\end{array}\right),\left(\begin{array}{lll}2 & 1 & 0\end{array}\right) \cup\left(\begin{array}{llll}1 & 0 & 1 & 4\end{array}\right),\left(\begin{array}{llll}7 & 5 & 4 & 3\end{array}\right)$.clearly $\mathrm{M}$ is a biset..

\subsection{Definition}

let $A_{1}=\left(a_{1}, a_{2} \ldots, a_{n}\right), A_{2}=\left(a_{1}^{\prime}, a_{2}^{\prime} \ldots, a_{n}^{\prime}\right) \quad$ be two vectors of length $n$ and $m$ respectively. Then $A=A_{1} \cup A_{2}$ is a

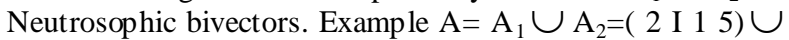
(2 8I 5 4), A is a Neutrosophic bivectors.

\subsection{Definition}

Let $\mathrm{G}$ is said to be bigraph where $\mathrm{G}=\mathrm{G}_{1} \cup \mathrm{G}_{2}$

\subsection{Definition}

Let $F=F_{1} \cup F_{2}$ be a Neutrosophic bimatrix. Then the bitranspose of the bimatrix $\mathrm{F}$ is defined as $F^{t}=\left(F_{1} \cup F_{2}\right)^{t}=F_{1}^{t} \cup F_{2}^{t}$

\subsection{Definition}

A Neutrosophic Associative Fuzzy Cognitive Map(NAFCM) is a directed bigraph with concepts like policies, events as a nodes and causalities as edges. It represents causal relationship between concepts. In a NAFCM the pair of associated nodes as binodes. If the order of the bimatrix associated with the NAFCM is a $\mathrm{p} \times$ m matrix and a $\mathrm{n} \times \mathrm{n}$ square matrix then the binodes are bivectors of length $(m, n)$ or $(\mathrm{p}, \mathrm{n})$.

\subsection{Definition}

Consider the binodes $\left\{\mathrm{C}_{1}, \mathrm{C}_{2} \ldots, \mathrm{C}_{\mathrm{n}}\right\}$ and $\left\{\mathrm{E}_{1}, \mathrm{E}_{2} \ldots, \mathrm{E}_{\mathrm{n}}\right\}$ of the NAM and $\left\{A_{1}, A_{2} \ldots, A_{n}\right\}$ of the FCM of the NAFCM of the bimodal. The bimatrix $\mathrm{F}=\mathrm{F}_{1} \cup \mathrm{F}_{2}$ is defined as $e_{i j}^{1} \cup e_{m n}^{2}$ where $e_{i j}^{1}$ is the directed edge of $C_{i} E_{j}$ and $e_{m n}^{2}$ is the directed edge of $A_{m} A_{n} . \mathrm{F}=\mathrm{F}_{1} \cup \mathrm{F}_{2}$ is called as adjacency matrix.

\subsection{Definition}

Simple NAFCM consist edge biweights $\{1,0,-1, I\}$. Let $\left\{\left\{\mathrm{C}_{1}, \mathrm{C}_{2} \ldots, \mathrm{C}_{\mathrm{n}}\right\}, \quad\left\{\mathrm{E}_{1}, \mathrm{E}_{2} \ldots, \mathrm{E}_{\mathrm{n}}\right\}\right\} \cup\left\{\mathrm{A}_{1}, \mathrm{~A}_{2} \ldots, \mathrm{A}_{\mathrm{n}}\right\}$ be the binodes of an NAFCM. $A=A_{1} \cup A_{2}=\left\{C_{1}, C_{2} \ldots, C_{n}\right\}$ 
or $\left\{\mathrm{E}_{1}, \mathrm{E}_{2} \ldots, \mathrm{E}_{\mathrm{n}}\right\} \cup\left\{\mathrm{A}_{1}, \mathrm{~A}_{2} \ldots, \mathrm{A}_{\mathrm{n}}\right\}$ where $\mathrm{C}_{\mathrm{i}}, \mathrm{E}_{\mathrm{j}}, \mathrm{A}_{\mathrm{m}} \in\{0,1, \mathrm{I}\}$. $1 \leq i \leq l, 1 \leq j \leq n, 1 \leq m \leq k$. A is called instantaneous state bivectors and it denotes ON-OFF-INDETERMINATE position of the node at an instant.

$C_{i}=0, E_{j}=0, A_{m}=0$ if $\mathrm{C}_{\mathrm{i}}, \mathrm{E}_{\mathrm{j}}, \mathrm{A}_{\mathrm{m}}$ are in off position. $C_{i}=1, E_{j}=1, A_{m}=1$ if $\mathrm{C}_{\mathrm{i}}, \mathrm{E}_{\mathrm{j}}, \mathrm{A}_{\mathrm{m}}$ are in on position

$C_{i}=I, E_{j}=I, A_{m}=I$ if $\mathrm{C}_{\mathrm{i}}, \mathrm{E}_{\mathrm{j}}, \mathrm{A}_{\mathrm{m}}$ are in Indeterminate position.

\subsection{Definition}

Let $\left\{\left\{\mathrm{C}_{1}, \mathrm{C}_{2} \ldots, \mathrm{C}_{\mathrm{y}}\right\},\left\{\mathrm{E}_{1}, \mathrm{E}_{2} \ldots, \mathrm{E}_{\mathrm{q}}\right\}\right\} \cup\left\{\mathrm{A}_{1}, \mathrm{~A}_{2} \ldots, \mathrm{A}_{\mathrm{n}}\right\}$ be the binodes of an NAFCM. Let $\mathrm{C}_{\mathrm{o}} \mathrm{E}_{\mathrm{p}} \cup \mathrm{A}_{\mathrm{c}} \mathrm{A}_{\mathrm{s}}$ be the biedges where $1 \leq o \leq y, 1 \leq p \leq q, 1 \leq \mathrm{c}, 1 \leq \mathrm{s}(\mathrm{s} \neq \mathrm{c})$. Then the bied ges form bidirected cycle. A NAFCM is said to be bicylic if it possesses a directed bicycle.

\subsection{Definition}

If the NAFCM settles down with a bistate, bivectors repeats in the form of $C_{1} \rightarrow C_{2} \rightarrow \ldots . . C_{i} \rightarrow C_{1}$ or $E_{1} \rightarrow E_{2} \rightarrow \ldots \ldots E_{J} \rightarrow E_{1} \cup A_{1} \rightarrow A_{2} \rightarrow \ldots . . A_{m} \rightarrow A_{1}$ then this equilibrium is called as limit bicycle.

\subsection{Definition}

The biedges $\mathrm{e}_{\mathrm{ij}}=\left(e_{m n}^{1}\right) \cup\left(e_{i j}^{2}\right)$ takes the values in fuzzy casual binterval $[-1,1] \cup[-1,1] \cup \mathrm{I}$.

$e_{i j}=0$ indicates no causality occurs between the binodes

$e_{i j}>0$ indicates that $\left(e_{m n}^{1}\right)>0$ and $\left(e_{i j}^{2}\right)>0$ implies that increase in the binodes $\mathrm{Ci} \cup \mathrm{Xk}$ (or Ys) implies increase in the binodes $\mathrm{Ci} \cup \mathrm{Xs}\left(\right.$ or $\left.\mathrm{Y}_{\mathrm{k}}\right)$

$e_{i j}<0$ indicates that $\left(e_{m n}^{1}\right)<0$ and $\left(e_{i j}^{2}\right)<0$ implies that decrease in the binodes $\mathrm{C}_{\mathrm{i}} \cup \mathrm{X}_{\mathrm{k}}\left(\right.$ or $\mathrm{Y}_{\mathrm{s}}$ ) implies decrease in the binodes $\mathrm{C}_{\mathrm{i}} \cup \mathrm{X}_{\mathrm{s}}$

$e_{i j}=$ I indicates Indeterminate position occurs between the binodes.

We can also have possibilities other than $e_{i j}=0, e_{i j}>0, e_{i j}$ $<0$

$e_{i j}=\left(e_{m n}^{1}\right) \cup\left(e_{i j}^{2}\right)$ if $\left(e_{m n}^{1}\right)>0$ and $\left(e_{i j}^{2}\right)=0$. Indicates that no relation in $\left(e_{i j}^{2}\right)$ and increase in $\left(e_{m n}^{1}\right)$

$e_{i j}=\left(e_{m n}^{1}\right) \cup\left(e_{i j}^{2}\right)$ if $\quad\left(e_{m n}^{1}\right)<0$ and $\left(e_{i j}^{2}\right)=0$. Indicates that no relation in $\left(e_{i j}^{2}\right)$ and decrease in $\left(e_{m n}^{1}\right)$

$e_{i j}=\left(e_{m n}^{1}\right) \cup\left(e_{i j}^{2}\right)$ we can have $\left(e_{m n}^{1}\right)>0$ and $\left(e_{i j}^{2}\right)$ $\leq 0$

$$
\begin{aligned}
& e_{i j}=\left(e_{m n}^{1}\right) \cup\left(e_{i j}^{2}\right) \text { we can have }\left(e_{m n}^{1}\right)=0 \text { and }\left(e_{i j}^{2}\right) \\
& <0 \\
& e_{i j}=\left(e_{m n}^{1}\right) \cup\left(e_{i j}^{2}\right) \text { we can have }\left(e_{m n}^{1}\right)=0 \text { and }\left(e_{i j}^{2}\right)> \\
& 0 \\
& e_{i j}=\left(e_{m n}^{1}\right) \cup\left(e_{i j}^{2}\right) \text { we can have }\left(e_{m n}^{1}\right)=0 \text { and }\left(e_{i j}^{2}\right)> \\
& 0
\end{aligned}
$$

In NAFCM there are nine possibilities where as in NAM or FCM there are only four possibilities. Thus extra possibilities make the resultant more sensible

\section{ADAPTATION OF THE MODEL}

The bimodel NAFCM consists of NAM and FCM in which Y be the connection bimatrix. Let $\mathrm{X}_{1}$ be the input bivectors which is in ON State and all other components are kept in OFF state. Pass the state vector $\mathrm{X}_{1}$ into connection bimatrix and convert the resultant vector into signal function by using thresholding process. choose one highest values in NAM as 1 and all other values as 0 . similarly follow the same process in FCM . The resulting vector which is obtained in NAM is multiplied with $\mathrm{M}^{\mathrm{T}}$ and thresholding yields new vector $\mathrm{X}_{2}$ where as the resulting vector is kept as it as in FCM. The process has been repeated for all the vectors separately. In NAM, the domain space consists of attributes related to problems faced by women entrepreneurs are denoted as $\mathrm{P}_{1}, \mathrm{P}_{2}, \mathrm{P}_{3}, \mathrm{P}_{4}, \mathrm{P}_{5}, \mathrm{P}_{6}, \mathrm{P}_{7}$.The effects are as $\mathrm{E}_{1}, \mathrm{E}_{2}, \mathrm{E}_{3}, \mathrm{E}_{4}, \mathrm{E}_{5}, \mathrm{E}_{6}$ in the range space. FCM consists of main attributes and denoted as $A_{1}, A_{2}, A_{3}, A_{4}, A_{5}, A_{6}, A_{7}$.

The attributes related to the problem of women entrepreneurs

$\mathrm{P}_{1}-$ Financial problems

$\mathrm{P}_{2}$ M arketing problems

$\mathrm{P}_{3-}$ Lack of Motivation from family

$\mathrm{P}_{4-}$ Casteism

$\mathrm{P}_{5-}$ Heavy competition

$\mathrm{P}_{6-}$ Patriarchal society

$\mathrm{P}_{7 \text { - Limited mobility }}$

Effects in the family

$\mathrm{E}_{1-\text { Lack of Confidence }}$

$\mathrm{E}_{2-}$ Psy chological Problems

$\mathrm{E}_{3-}$ - Family Conflicts

$\mathrm{E}_{4-}$ Divorce

$\mathrm{E}_{5-}$ Opportunities are denied

$\mathrm{E}_{6-}$ Domestic Violence

Major problems faced by women entrepreneurs

$\mathrm{A}_{1}$ - Lack of Finance

$\mathrm{A}_{2}$-Family Conflicts

$\mathrm{A}_{3}$-Lack of support in family

$\mathrm{A}_{4}$-Lack of Mental Strength

$\mathrm{A}_{5}$ - Lack of Education

$\mathrm{A}_{6}$ - Family Restriction 
$\mathrm{A}_{7}$ - Low risk bearing ability

The expert's opinion is given in the form of connection Bimatrix Y

$$
\begin{aligned}
& \left.\begin{array}{rllccl}
E_{1} & E_{2} & E_{3} & E_{4} & E_{5} & E_{6} \\
0.7 & 0.8 & 0.6 & 0 & 0 & 0.2
\end{array}\right] \quad C_{1}\left[\begin{array}{lllllll}
0 & 1 & 1 & 1 & 1 & 0 & 1 \\
0.6 & 07 & 0 . & 0 & 0 & 0
\end{array}\right] \\
& P_{2}\left|\begin{array}{cccccc}
0.6 & 0.7 & 0.2 & 0 & 0 & 0
\end{array} \quad C_{2}\right| \begin{array}{lllllll}
1 & 0 & 1 & 1 & 0 & 1 & 0
\end{array}
\end{aligned}
$$

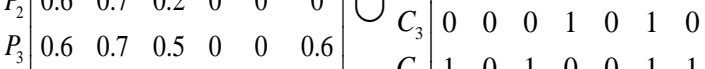

$$
\begin{aligned}
& Y=P_{4} \mid \begin{array}{lllllll}
0.3 & 0.4 & 0 & 0 & 0.5 & 0.2
\end{array} \\
& P_{5} \quad \begin{array}{llllll}
0.4 & 0.5 & 0 & 0 & 0 & 0
\end{array} \\
& \begin{array}{l|llllll}
P_{6} & 0.2 & 0.3 & 0.4 & 0 & 0.2 & 0.1
\end{array} \\
& P_{7}\left[\begin{array}{llllll}
0.3 & 0.4 & 0.3 & I & 0.1 & 0.5
\end{array}\right] \\
& C_{4} \mid \begin{array}{lllllll}
C_{4} & 0 & 1 & 0 & 0 & 1 & 1
\end{array} \\
& C_{5} \mid \begin{array}{lllllll}
1 & 0 & 0 & 0 & 0 & 0 & 0
\end{array} \\
& C_{6} \mid \begin{array}{lllllll}
0 & 1 & 1 & 1 & 0 & 0 & 1
\end{array} \\
& C_{7}\left[\begin{array}{lllllll}
1 & 1 & 1 & 0 & 0 & 1 & 0
\end{array}\right] \\
& \mathrm{Y}=\mathrm{Y}_{1} \cup \mathrm{Y}_{2}
\end{aligned}
$$

Let $\mathrm{X}_{1}$ is kept in ON state where other nodes are in OFF state

$$
\begin{aligned}
& \mathrm{X}_{1}=(1000000) \cup(1000000) \\
& \mathrm{X}_{1} \cdot \mathrm{M}=(1000000) . \mathrm{Y}_{1} \cup(1000000) . \mathrm{Y}_{2}
\end{aligned}
$$

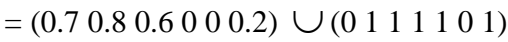

$$
\begin{aligned}
& \hookrightarrow\left(\begin{array}{llllll}
0 & 1 & 0 & 0 & 0 & 0
\end{array}\right) \cup\left(\begin{array}{lllllll}
0 & 1 & 1 & 1 & 1 & 0 & 1
\end{array}\right) \\
& =\left(\begin{array}{llllll}
0 & 1 & 0 & 0 & 0 & 0
\end{array}\right) . Y_{1}^{T} \cup\left(\begin{array}{lllllll}
0 & 1 & 1 & 1 & 1 & 0 & 1
\end{array}\right) . Y_{2}
\end{aligned}
$$

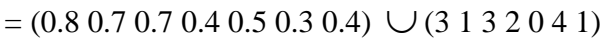

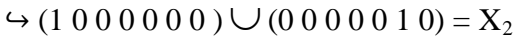

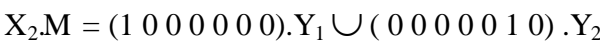

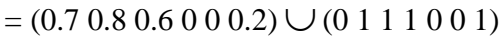

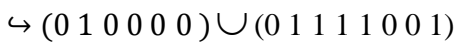

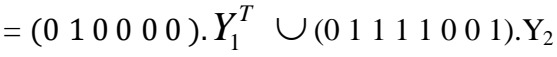

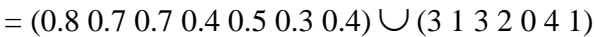

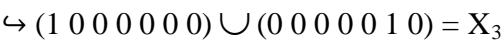

$\left(\begin{array}{llllll}0 & 1 & 0 & 0 & 0 & 0\end{array}\right),\left(\begin{array}{lllllll}1 & 0 & 0 & 0 & 0 & 0 & 0\end{array}\right) \cup\left(\begin{array}{lllllll}0 & 0 & 0 & 0 & 0 & 1 & 0\end{array}\right)$ is the fixed point

Table 1. The set of all limit points with respect to the different input vectors

\begin{tabular}{|l|l|}
\hline Input Vectors & Limit Points \\
\hline$(1000000)$ & $(010000),(1000000) \cup(0000010)$ \\
\hline$(0100000)$ & $(010000),(1000000) \cup(0000010)$ \\
\hline$(0010000)$ & $(010000),(1000000) \cup(0000010)$ \\
\hline
\end{tabular}

\begin{tabular}{|l|l|}
\hline$(0001000)$ & $(000010),(0001000) \cup(0000010)$ \\
\hline$(0000100)$ & $(010000),(1000000) \cup(0000010)$ \\
\hline$(0000010)$ & $(010000),(1000000) \cup(0111001)$ \\
\hline$(0000001)$ & $(010 \mathrm{I} 00),(1000001) \cup(0000010)$ \\
\hline
\end{tabular}

\section{CONCLUSIONS}

We analyzed the problems faced by women entrepreneurs by using NAFCM, it highlights $\mathrm{P}_{1}$ (Financial problems $), \mathrm{P}_{4}$ (Casteism), $\quad \mathrm{P}_{7}($ Limited mobility $)$, $\mathrm{E}_{2}$ (Psy chological Problems), $\mathrm{E}_{5}$ (Opportunities are denied),but $\mathrm{E}_{4}$ is in Indeterminate position and $\mathrm{A}_{2}$ (Family Conflicts) $\mathrm{A}_{3}$ (Lack of support in family), $\mathrm{A}_{4}$ (Lack of Mental Strength) $\mathrm{A}_{6}$ (Family Restriction), $\mathrm{A}_{7}$ (Low risk bearing ability) are the problems and effects faced by them.

\section{ACKNOWLEDGMENTS}

This research work is supported by UGC Scheme RGNF Award letter NoF1-17.1/2016-17/RGNF-2015-17-SC-TAM18451/(SA-III Website)

\section{REFERENCES}

[1] L.A.Zadeh Fuzzy sets, Information control, pp 338353,1965 .

[2] Axelrod, Structure of decision, The Cognitive maps of political elities, Princeton, NJ: Princeton University Press.

[3] W.B. Vasantha Kandasamy et all, Mathematical Analysis of the problems faced by the people with disabilities, Ph.D thesis, University of Madras

[4] Thirusangu et all, A New bidirectional Associative Fuzzy Cognitive Dynamical system, Indian Journal of science and technology, 2012.

[5] A.Victor Devadoss, A. Felix, A new Bidirectional Associative Neutrosophic Cognitive Dynamical system approaches to study youth violence, international Journal of computer Applications, Vol 53, no 11, Sep 2012.

[6] A.Victor Devadoss, M.Rekha, A Study on Child marriage using New Neutrosophic Associative Fuzzy Cognitive Dynamical Sy stem, Global Journal of Pure and Applied Mathematics, ISSN: 0973-1768, Volume(13), Number (6) 2017, 2255-2265.

[7] The Indian Express, India Ranks low among Countries with Women Entrepreneurs, ,July 2018. 